\title{
Risk of Obstructive Sleep Apnea and Risk Factors in Patıents with Type 2 Diabetes in Turkey
}

\author{
By Ylldız Denat ${ }^{*}$ \& Zeynep Güneş ${ }^{ \pm}$
}

\begin{abstract}
The study was conducted to unveil the relation between the risk of sleep apnea and risk factors for type 2 diabetes in adult patients. The sample consisted of 228 patients with type 2 diabetes. It was found out that the patients had diabetes for $10.93 \pm 7.30$ years on average, $47.4 \%$ received insulin treatment and $89.5 \%$ had no history of sleep apnea in their family. Results revealed that 58.8\% of the patients had a high risk for sleep apnea, those belonging to the male gender increased the obstructive sleep apnea risk by 4-fold compared to the female gender, and a unit increase in the body mass index increased the obstructive sleep apnea risk by 1.1-fold. It was also found that having hypertension increased the risk of obstructive sleep apnea by 5-fold and the patients who experienced excessive daytime sleepiness had 11.2 times higher risk of obstructive sleep apnea.
\end{abstract}

Keywords: Diabetes, Nursing care, Obstructive sleep apnea, Sleep apnea

\section{Introduction}

Obstructive sleep apnea (OSA) is a really common disorder that is identified by recurrent episodes of upper airway obstruction developing during sleep (Garvey et al. 2015). In the studies conducted the incidence of OSA was found to be between $14 \%$ and $49 \%$ in male patients, and 9\% in females (Young et al. 1993, Garvey et al. 2015, Qie et al. 2020). In many other studies, similar prevalence rates were reported, with higher rates in males (Barve et al. 2018, Heinzer et al. 2015, Pamidi and Tasali 2012, Senaratna et al. 2017). It has been found out that there have been different risk factors in the process of OSA, but undeniably the biggest risk factor is obesity (Barve et al. 2018, Qie et al. 2020, Tishler et al. 2003, Newman et al. 2005; Senaratna et al. 2017). Obesity is also a risk factor for type 2 diabetes. Patients with type 2 diabetes have an increased risk of OSA, unfortunately, many are undiagnosed (Jehan et al. 2018). Besides, OSA is also associated with sleep-disordered breathing (SDB), insulin resistance, and glucose intolerance. It is estimated that $83 \%$ of patients with type 2 diabetes have complained of OSA (Pamadi and Tasali 2012; Barve et al. 2018, Qie et al. 2020). Cass et al. (2013) emphasized in their study that almost half of adults with type 2 diabetes may have high risk for OSA which may not have been diagnosed.

In this regard, there are a limited number of studies in Turkey. In a study, it is recommended to investigate the presence of diabetes in all patients diagnosed with OSA and to evaluate it in terms of OSA in patients diagnosed with diabetes (Binici et al. 2016).

\footnotetext{
*Associate Professor, Aydın Adnan Menderes University, Turkey.

${ }^{ \pm}$Professor, Aydın Adnan Menderes University, Turkey.
} 
It is known that the presence of OSA is not assessed routinely in individuals with diabetes. It was emphasized in an article that to prevent respiratory sleep disorder and type 2 diabetes, health professionals must pay attention to the association of these two cases in their current practice. There is a need for more data from extensive longitudinal studies in which diabetes and OSA are evaluated meticulously (Cass et al. 2013, Pamidi and Tasali 2012, Hamilton and Naughton 2013).

For this reason, this study was planned to determine the risk and risk factors of sleep apnea in the patients with type 2 diabetes.

\section{Methodology}

Study Design

The study is a cross-sectional analytical study. The study was conducted between 01/03/2016 and 15/07/2016. The population of the study consisted of the adult patients with type 2 diabetes who applied to the diabetes polyclinic of a Public Hospital located in the west of Turkey between 01/03/2016 and 15/07/2016.

\section{Participants and Setting}

The sample of the study consisted of 228 patients who accepted to participate in the study, and who were 18 years or older, cognitively competent, able to speak Turkish, and were being monitored for diagnosis of type 2 diabetes in the Diabetes Policlinic of Public Hospital between 01/03/2016 and 15/07/2016. Since there is no study that examines the relationship of patients with type- 2 diabetes with OSA markers as excessive sleepiness, snoring, witnessed apnea, the effect size calculation could not be carried out in the study.

The data of study was gathered by the researchers through face-to-face interview with the patients diagnosed with type 2 diabetes in Diabetes Polyclinic of a Public Hospital located in the west of Turkey between 01/03/2016 and15/07/2016. The research data was collected by an independent researcher.

\section{Ethics Approval}

Approval was received from Adnan Menderes University Faculty of Medicine Non-Interventional Clinical Research Ethics Committee (approval no. 53043469/050.04-108). The informed consent forms were signed earlier to include the research participants.

\section{Measurement Tools}

In this study, the data were gathered by using the "Patient Information Form" and the "Berlin Questionnaire" in which the risk of sleep apnea was evaluated. 
Patient Information Form: This form was comprised of two parts. The first part collected information about the diabetes mellitus of the patients and their socio-demographic characteristics. The second part contained questions about smoking-alcohol consumption and body mass index, neck and waist circumference, hypertension, snoring and excessive daytime sleeping that are considered among the risk factors of Obstructive Sleep Apnea Syndrome (OSAS), and about other diseases which the patients have.

Berlin Questionnaire: It is a questionnaire created to screen the community for OSAS by a consensus gathered in the "First Stage Sleep Conference" held in Berlin-Germany in 1996. The validity and reliability of the "Berlin Questionnaire" in the Turkish population was carried out by Acar et al. (2013). The sensitivity of the "Berlin Questionnaire" was found as $87.9 \%$ in the study which analyzed the sensitivity of the "Berlin Form" as a screening test in OSA. The "Berlin Questionnaire" contains 10 items in three categories. The first category contains questions on snoring and witnessed apnea (5 items), the second category questions daytime sleepiness ( 4 items), while the third category asks questions on blood pressure/obesity ( 1 item). If the response to at least two items in the first two categories is answered as "yes," that category is considered positive (+). The third category is considered positive if the blood pressure level is answered as "yes" or if the body mass index (BMI) is $\geq 30$. If two or three categories are positive, the patient is at high risk for OSAS, and if only one category is positive, the patient is at low risk for OSAS (Acar et al. 2013, Demir et al. 2012).

\section{Data Analysis}

The data of study were examined through the Statistical Package for Social Sciences (SPSS) for Windows 11.5 package program. The results were revealed as sample number $(\mathrm{N})$, percentage $(\%)$, and significant $p$ values. Binary logistic regression analysis that it was determined which variables predicted high risk for OSA and type 2 diabetes with enter methods. Variables such as excessive sleepiness, smoking, gender, alcohol consumption, snoring were evaluated in two categories. The cut off point for excessive daytime sleepiness is considered to be equalor greater than 10 (Andrechuk and Ceolim 2015). The findings were assessed at $95 \%$ confidence interval and significance level $p<0.05$.

\section{Results}

It was found that the average age of the patients participating in the study was $54.45 \pm 11.46$ and $63.2 \%(n=144)$ of the patients were female. Most of the patients were married $(\mathrm{n}=202 ; 88.6 \%), 78.5 \%(\mathrm{n}=179)$ were primary and secondary school graduates and $80.7 \%(\mathrm{n}=184)$ did not work. A larger percentage of the patients $(n=144 ; 63.2 \%)$ had an illness other than diabetes and of this group, 38.2\% $(n=87)$ had hypertension. Nearly all the patients $(\mathrm{n}=206 ; 90.4 \%)$ did not drink alcohol, $82 \%(n=187)$ were non-smokers and 91.2\% $(n=208)$ had BMIs greater than 30. It was found that the patients had diabetes for $10.93 \pm 7.30$ years on average, $47.4 \%$ 
$(n=108)$ received insulin treatment and $89.5 \%(n=204)$ had no history of sleep apnea in their family. When the risks of OSA of the patients in this study was examined according to the Berlin Questionnaire, it was found out that 58.8\% $(n=134)$ of the patients had a high risk and $41.2 \%$ (94) of the patients had no risk (Table 1).

Table 1. Risk Levels of OSA of Patients $(n=228)$

\begin{tabular}{|l|c|c|}
\hline Risk Evaluation & N & \% \\
\hline Risk Levels According to Berlin Questionnaire & \multicolumn{2}{|l|}{} \\
\hline No Risk & 94 & 41.2 \\
\hline High Risk & 134 & 58.8 \\
\hline
\end{tabular}

Table 2. Evaluation of OSA Risk Factors through Logistic Regression Analysis $(n=228)$

\begin{tabular}{|l|c|c|}
\hline Risk Factors & Sig. & OR (95\% CI) \\
\hline Age & 0.81 & $1.005(0.966-1.045)$ \\
\hline Gender & $\mathbf{0 . 0 5}$ & $\mathbf{4 . 0 2 9}(\mathbf{0 . 9 8 5}-\mathbf{1 6 . 4 8 6})$ \\
\hline Body Mass Index & $\mathbf{0 . 0 5}$ & $\mathbf{1 . 1 1 0}(\mathbf{0 . 0 9 9 9}-\mathbf{1 . 2 3 4})$ \\
\hline Waist & 0.88 & $1.002(0.975-1.030)$ \\
\hline Neck & $\mathbf{0 . 0 0}$ & $\mathbf{1 . 3 4 4}(\mathbf{1 . 1 0 2}-\mathbf{1 . 6 4 0})$ \\
\hline Alcohol & 0.81 & $0.795(0.122-5.171)$ \\
\hline Smoking & 0.77 & $0.809(0.192-3.410)$ \\
\hline Hypertension & $\mathbf{0 . 0 0}$ & $\mathbf{5 . 7 6 0}(\mathbf{1 . 7 7 9}-\mathbf{1 8 . 6 4 4})$ \\
\hline Snoring & 0.28 & $1.764(0.619-5.028)$ \\
\hline Excessive Daytime Sleepiness & $\mathbf{0 . 0 1}$ & $\mathbf{1 . 1 3 9}(\mathbf{1 . 0 2 4}-\mathbf{1 . 2 6 7})$ \\
\hline Sleep Apnea & 0.06 & $8.418(0.846-83.752)$ \\
\hline
\end{tabular}

Table 2 shows the findings of logistic regression analysis in which the independent variables, which have significance in univariate analysis, are involved in the model. In the logistic regression analysis performed by the Enter method, the male gender has 4 times higher OSA risk than the female gender $(\mathrm{OR}=12.351$; $\mathrm{CI}=3.450-44.218 ; p=0.000)$. One unit increase in BMI increases the OSA risk by 1.1-fold ( $\mathrm{OR}=1.194 ; \mathrm{CI}=1.079-1.322 ; p=0.001)$. Hypertension increases the OSA risk by 5 -fold $(\mathrm{OR}=5.962 ; \mathrm{CI}=1.887-18.839 ; p=0.002)$. The risk of OSA is 11.2 times higher in the patients with excessive daytime sleepiness than in those without it $(\mathrm{OR}=11.232 ; \mathrm{CI}=1.092-115.535 ; p=0.042)$.

\section{Discussion}

OSA is a disease that is very common in patients with type 2 diabetes (Tahrani and Ali 2013). It is estimated that $83 \%$ of the patients with type 2 diabetes have laid an unspecified OSA complaint (Pamidi and Tasalini 2012). In the study carried out by Einhorn et al. (2007) it was found that in a population of 279 people enrolled in a diabetes clinic, $48 \%$ of the adults with type 2 diabetes had OSA. Vale et al. (2015) found in their study conducted using polysomnography that $63 \%$ of the patients with type 1 and type 2 diabetes had OSA. It was also 
reported that as the severity of OSA increased, glycemic control worsened. A systematic meta-analysis revealed that OSA increased the risk of developing type 2 diabetes by 2.02 -fold $(95 \%$ CI, 1.57, 2.61) (Anothaisintawee et al. 2016). In this study, the aim was to evaluate adult patients with type 2 diabetes for the risk of sleep apnea as well as its risk factors. We found that $58.8 \%$ of the patients had high OSA risk. This was similar to the results by Cass et al. (2013) where $12.5 \%$ of the patients with type 2 diabetes had been formerly diagnosed with OSA and $48.6 \%$ of the remaining patients had a high risk for OSA. It was found in many studies that OSA was connected with insulin resistance (IR) (Hermans et al. 2013) in the patients with type 2 diabetes (Rudrappa et al. 2012, Shiba et al. 2010, Altaf et al. 2013). Similar results were also detected in weak individuals supporting that the relation between IR and OSA was independent of obesity (Lin et al. 2012, Pamidi and Tasali 2012). Several studies showed that OSA and OSA severity were connected with poorer glycemic control (HbA1c and/or fasting plasma glucose) although confounders were regulated in some studies (Aronsohn et al. 2010, Barve et al. 2018, Qie et al. 2020, Drager et al. 2009, Kosseifi et al. 2010, Papanas et al. 2009, Pillai et al. 2011). OSA is thought to have a significant part in the development and growth of diabetic microvascular complications since OSA is connected with most of the pathophysiological deficits existing in diabetes (Qie et al. 2020, Altaf et al. 2013, Tahrani and Ali 2014, Tahrani et al. 2012). It is well known that the incidence of OSA in male patients is higher than in women. Most of the population-based studies show that men have 2-3 times higher prevalence of OSA (Punjabi 2008). In our study, it was also found that men had 4 times higher OSA risk than women (Table 2). In the study conducted by West et al. (2006) using the Berlin Questionnaire, 57\% of the men with type 2 diabetes were found to have high OSA risk. In the study carried out by Young et al. (1993), it was found the incidence of OSA was 24\% in males between 30-60 years and only $9 \%$ in females. Garvey et al. (2015) found the incidence of OSA in males to be between $14 \%$ and $49 \%$ while Punjabi found OSA prevalence in females to be 25\% (Punjabi 2008). In many other studies, similar prevalence rates were observed, with higher rates in males (Lee et al. 2008, Senaratna et al. 2017; Heinzer et al. 2015, Jennum and Riha 2009, Sharma et al. 2006). It seems in the studies that this gender gap narrows after menopause (Bixler et al. 2001, Sharma et al. 2006). Indeed, it is stated in the literature that sex hormones may play a critical part in the pathogenesis of OSA, that OSA is more common in postmenopausal women than in premenopausal women, and that hormone replacement therapy in postmenopausal women may be protective against the disorder (Wesström et al. 2005). Also, it is more likely that male patients are referred for clinical assessment for OSA, perhaps as physicians seem to possess a higher index of suspicion for considering the disorder in male patients.

Obesity is typically accepted as one of the biggest risk factors of OSA (Garvey et al. 2015, Newman et al. 2005, Punjabi 2008, Tishler et al. 2003, Young et al. 2005). OSA is a sleep disorder that can be treatable and is common among overweight and obese adults representing nearly two-thirds of the US population today (Young et al. 2005). In the study conducted by Vgontzas et al. (1994), 50\% of obese patients were found to have OSA, and Young et al. (2005) confirmed that 
the incidence of OSA increased by 30-60\% in obese patients. Forty-one percent of patients with a BMI more than 28 have OSA and the incidence can be as high as $78 \%$ in the patients referred for bariatric surgery (Lopez et al. 2008; Schwartz et al. 2010). It was determined in the systematic review conducted by Senaratna et al. (2017) to find out the incidence of OSA in the general population that the incidence of OSA was higher in obese male and female patients. The estimated incidence of OSA in obese adults (30-69 years) is $11-46 \%$ in female patients and 33-77\% in male patients (Young et al. 2005). Furthermore, weight gain predicts the severity of increased OSA incidence (Newman et al. 2005, Peppard et al. 2000). A $10 \%$ weight gain in the individuals who initially had no OSA or moderate OSA (apnea-hypopnea index, AHI $<15)$ increased the likelihood of developing moderate or severe OSA (AHI $\geq 15$ ) by 6-fold (95\% CI, 2-17) (Peppard et al. 2000). In the Wisconsin Sleep Cohort study, weight gain over a 4-year period was a significant predictor of OSA development; a $10 \%$ rise in body weight conferred a $32 \%$ rise in $\mathrm{AHI}$ and a 6-fold rise in the risk for developing moderatesevere OSA (Peppard et al. 2000). In the Sleep Heart Health Study, a multi-centre epidemiologic cohort study of cardiovascular correlates of OSA in middle-aged and older Americans, weight gain of 10 kilograms over a 5-year period conferred a 5.2- and 2.5-fold rise on the possibility of increasing the AHI by 15 events per hour in male and female patients, respectively (Newman et al. 2005). It was found in our study that one unit rise in the BMI of the patients with type 2 diabetes increased the OSA risk by 1.1-fold (Table 2). In the study by Cass et al. (2013) BMI of the type 2 diabetes patients with high-risk of OSA was found to be greater than 30. Various studies showed a rise in OSA incidence as well as a rise in body habitus measurements (Bixler et al. 2001, Young et al. 2002). For each unit rise in the BMI, the OSA development odds ratio is 1.14 (95\% CI, 1.10-1.19). However, the impact of the BMI on OSA becomes less significant after 60 years of age (Tishler et al. 2003). The systematic compilation of general proof certifies that advancing age, male gender, and higher body mass index increase the OSA prevalence (Senaratna et al. 2017). Given the obesity pandemic in Western society, it is likely that the incidence of OSA increases further.

Population-based cross-sectional and prospective longitudinal studies have shown a firm and independent correlation in the separate measurements of OSA severity (measurements of AHI and oxygenation) in individuals with hypertension. In a cross-sectional study based on two large populations, the participants with moderate or severe OSA (AHI $\geq 15)$ were found to have an odds ratio of 1.42 to 1.72 for hypertension, when compared to those without any OSA (AHI $<1.5)$, after BMI and other known variables were established (Bixler et al. 2000, Nieto et al. 2000, Qie et al. 2020). Our study also found that hypertension increased OSA risk by 5 -fold (Table 2). Cass et al. (2013) found that $96.2 \%$ of type 2 diabetes patients with high risk of OSA had hypertension. After controlling for varied known confounders (age, body habitus, baseline hypertension, alcohol, and smoking), it was determined that in comparison with the subjects without OSA, the adjusted odds ratio for hypertension was 2.03 for mild OSA (95\% CI, 1.29-3.17) and 2.89 for moderate or severe OSA (95\% CI, 1.46-5.64) (Peppard et al. 2000). Hamilton and Naughton (2013) noted in their articles evaluating OSA impact on diabetes 
and cardiovascular diseases that people with diabetes, stroke, cardiovascular disease, and uncontrolled hypertension were at high risk for OSA and stressed that OSA symptoms, need be questioned in these patients.

Snoring, excessive daytime sleepiness and witnessed apnea are three prevalent symptoms of OSA (Gupta and Wang 2016, Lee et al. 2017). In our study, OSA was found to be 11.2 times higher in the patients who experienced excessive daytime sleepiness than in those who did not (Table 2). The study by Cass et al. (2013) revealed that $64.5 \%$ of type 2 diabetes patients with high risk of OSA had excessive daytime sleepiness. A prospective cohort study of type 2 diabetes patients found the prevalence of excessive daytime sleepiness to be $35 \%$ (Vasconcelos et al. 2016), while in another study conducted on patients with type 1 and type 2 diabetes, the prevalence of excessive daytime sleepiness was $20.7 \%$ in the group with OSA (Vale et al. 2015).

\section{Study Limitations}

This study had some limitations. Firstly, the results of this study were limited to the patients participating in the study and cannot be generalised. Secondly, Berlin Questionnaire was used in this study. For this reason, the findings were based on the individuals' own statements. Furthermore, the absence of a control group caused limitations in the discussion of the results. The confounding factor of this study is the fact that the people, who apply to the hospital, do not have a specific universe, and the sample consists of those who apply to the hospital. Therefore, confounding factors may be higher than expected in our study.

\section{Conclusions}

The results in this study are helpful for clinical practice. They revealed that the adult patients with type 2 diabetes had high risk for OSA and those belonging to the male gender; increase in BMI, hypertension and excessive daytime sleepiness were important factors for OSA risk.

\section{References}

Acar V, Kaya, Yücel F, Erdem, M, Günal SE, Özgen F et al. (2013) Validation of the stop-bang questionnaire: an obstructive sleep apnoea screening tool in Turkish population. Turkish Journal of the Anaesthesiology and Reanimation 41(4): 115-120.

Altaf Q, Dodson PM, Ali A, Raymond NT, Fellows H, Hampshire M et al. (2013) Obstructive sleep apnoea is associated with sight threatening retinopathy and predicts the development of pre proliferative and retinopathy in patients with type 2 diabetes: a longitudinal analysis. Diabetic Medicine 30: E5-E5.

Andrechuk CRS, Ceolim MF (2015) Sleep quality and adverse outcomes for patients with acute myocardial infarction. Journal of Clinical Nursing 25(1-2): 223-230. 
Anothaisintawee T, Reutrakul S, Cauter EV, Thakkinstian A (2016) Sleep disturbances compared to traditional risk factors for diabetes development; systematic review and meta-analysis. Sleep Medicine Reviews 30(Dec): 11-24.

Aronsohn RS, Whitmore H, Van Cauter E, Tasali E (2010) Impact to fun treated obstructive sleep apnea on glucose controlin type 2 diabetes. American Journal of Respiratory and Critical Care Medicine 181(5): 507-513.

Barve K, Desai U, Jashi JM (2018) Obstructive sleep apnea and diabetes mellitus: a bitter combo. Indian Sleep Medicine 13(3): 48-52.

Binici DN, Kayabekir M, Timur Ö, Taşar PT, Kaygın MA, Arslan Z et al. (2016). Type 2 diabetes mellitus rate in patients diagnosed with obstructive sleep apnea syndrome. Turkiye Klinikleri Journal of Internal Medicine 1(2): 71-75.

Bixler EO, Vgontzas AN, Lin HM, Ten Have T, Leiby BE, Vela-Bueno A et al. (2000) Association of hypertension and sleep-disordered breathing. Archives of Internal Medicine 160(15): 2289-2295.

Bixler EO, Vgontzas AN, Lin HM, Ten Have T, Rein J, Vela-Bueno A et al. (2001) Prevalence of sleep-disordered breathing in women: effects of gender. American Journal of Respiratory and Critical Care Medicine 163(3): 608-613.

Cass AR, Alanson WJ, Islam J, Weller SC (2013) Risk of obstructive sleep apnea in patients with type 2 diabetes mellitus. Family Medicine 45(7): 492-500.

Demir A, Ursavaş A, Aslan AT, Gülbay B, Çiftçi B, Çuhadaroğlu Ç et al. (2012) Türk toraks derneği obstrüktif uyku apne sendromu tanı ve tedavi uzlaşı raporu (Turkish thoracic society obstructive sleep apnea syndrome diagnosis and treatment consensus report). Turkish Thoracic Journal 13(1): 1-73.

Drager LF, Queiroz EL, Lopes HF, Genta PR, Krieger EM, Lorenzi-Filho G (2009) Obstructive sleep apnea is highly prevalent and correlates with impaired glycemic control in consecutive patients with the metabolic syndrome. Journal of the Cardiometabolic Syndrome 4(2): 89-95.

Einhorn D, Stewart D, Erman M, Gordon N, Philis-Tsimikas A, Casal E (2007) Prevalence of sleep apnea in a population of adults with type 2 diabetes mellitus. Endocrine Practice 13(4): 355-362. DOI: 10.4158/EP.13.4.355.

Garvey JF, Pengo MF, Drakatos P, Kent BD (2015) Epidemiological aspects of obstructive sleep apnea. Journal of Thoracic Disease 7(5): 920-929.

Gupta S, Wang Z (2016) Predictors of sleep disorders among patients with type 2 diabetes mellitus. Diabetes Metabolic Syndrome 10(4): 213-220.

Hamilton GS, Naughton MT (2013) Impact of obstructive sleep apnoea on diabetes and cardiovascular disease. Medical Journal of Australia 199(8): 27-30.

Heinzer R, Vat S, Marques-Vidal P, Marti-Soler H, Andries D, Tobback N et al. (2015) Prevalence of sleep-disordered breathing in the general population: the hypnolaus study. Lancet Respiratory Medicine 3(4): 310-318.

Hermans MP, Ahn SA, Mahadeb YP, Rousseau MF (2013) Sleep apnoea syndrome and 10 -year cardiovascular risk in females with type 2 diabetes: relationship with insulin secretion and insulin resistance. Diabetes/Matabolism Research and Reviews 29(3): 227-234.

Jehan S, Myers AK, Zizi F, Pondi-Perumal SR, Jean-Louis G, McFarlane DI (2018) Obesity, obstructive sleep apnea and type 2 diabetes mellitus: epidemiology and pathophysiologic insights. Sleep Medicine and Disorders: International Journal 2(3): 54-60.

Jennum P, Riha RL (2009) Epidemiology of sleep apnoea/hyponoea syndrome and sleepdisordered breathing. European Respiratory Society 33(4): 907-914. 
Kosseifi S, Bailey B, Price R, Roy TM, Byrd RP, Peiris ANJ (2010) The Association between obstructive sleep apnea syndrome and microvascular complications in wellcontrolled diabetic patients. Military Medicine 175(11): 913-916.

Lee W, Nagubadi S, Kryger MH, Mokhlesi B (2008) Epidemiology of obstructive sleep apnea: a population-based perspective. Expert Review of Respiratory Medicine 2(3): 349-364.

Lee YH, Kweon SS, Choi JS, Nam HS, Park KS, Choi SW et al. (2017) Genderspecific association between self-reported snoring and hemoglobin A1c levels in a general population without type 2 diabetes mellitus. Yonsei Medical Journal 58(6): 1152-1159.

Lin QC, Zhang XB, Chen GP, Huang DY, Din HB, Tang AZ (2012) Obstructive sleep apnea syndrome is associated with some components of metabolic syndrome in nonobese adults. Sleep \& Breathing 16(2): 571-578.

Lopez PP, Stefan B, Schulman CI, Byers PM (2008) Prevalence of sleep apnea in morbidly obese patients who presented for weight loss surgery evaluation: more evidence for routine screening for obstructive sleep apnea before weight loss surgery. The American Journal of Surgery 74(9): 834-838.

Newman AB, Foster G, Givelber R, Nieto FJ, Redline S, Young T (2005) Progression and regression of sleep-disordered breathing with changes in weight: the sleep heart health study. Archives of Internal Medicine 165(20): 2408-2413.

Nieto FJ, Young TB, Lind BK, Shahar E, Samet JM, Redline S et al. (2000) Association of sleep-disordered breathing, sleep apnea, and hypertension in a large communitybased study sleep heart health study. JAMA 283(14): 1829-1836.

Pamidi S, Tasali E (2012) Obstructive sleep apnea and type 2 diabetes: is there a link? Frontiers in Neurology 13(3): 126.

Papanas N, Steiropoulos P, Nena E, Tzouvelekis A, Maltezos E, Trakada G et al. (2009) HbA1c is associated with severity of obstructive sleep apnea hypopnea syndrome in nondiabetic men. Journal of Vascular Health and Risk Management 5(Sep): 751-756.

Peppard PE, Young T, Palta M, Dempsey J, Skatrud J (2000) Longitudinal study of moderate weight change and sleep-disordered breathing. JAMA 284(23): 3015-3021.

Pillai A, Warren G, Gunathilake W, Idris I (2011) Effects of sleep apnea severity on glycemic control in patients with type 2 diabetes prior to continuous positive airway pressure treatment. Diabetes Technology and Therapeutics 13(9): 945-949.

Punjabi NM (2008) The epidemiology of adult obstructive sleep apnea. Proceeding of the American Thoracic Society 5(2): 136-143.

Qie R, Zhang D, Liu L, Yongcheng R, Zhao Y, Liu D et al. (2020) Obstructive sleep apnea and risk of type 2 diabetes mellitus: a systematic review and dose-response meta-analysis of cohort studies. Journal of Diabetes (Dec): 1-10.

Rudrappa S, Warren G, Idris I (2012) Obstructive sleep apnoea is associated with the development and progression of diabetic retinopathy, independent of conventional risk factors and novel biomarkers for diabetic retinopathy. British Journal of Ophthalmology 96(12): 1535.

Schwartz AR, Patil SP, Squier S, Schneider H, Kirkness JP, Smith PL (2010) Obesity and upper airway control during sleep. Journal of Applied Physiology 108(2): 430-435.

Senaratna CV, Perret J, Lodge CJ, Lowe AJ, Campbell BE, Matheson MC et al. (2017) Prevalence of obstructive sleep apnea in the general population: a systematic review. Sleep Medicine Reviews 34(Jul): 70-81.

Sharma SK, Kumpawat S, Banga A, Goel A (2006) Prevalence and risk factors of obstructive sleep apnea syndrome in a population of Delhi, India. Chest 130(1): 149-156. 
Shiba T, Maeno T, Saishin Y, Hori Y, Takahashi M (2010) Nocturnal intermittent serious hypoxia and reoxygenation in proliferative diabetic retinopathy cases. American Journal of Ophthalmology 149(6): 959-963.

Tahrani AA, Ali A (2013) Obstructive sleep apnea and diabetes: an update. Current Opinion in Pulmonary Medicine 19(6): 631-638.

Tahrani AA, Ali A (2014) Oxidative stress, inflammation and endothelial dysfunction: the link between obstructive sleep apnoea and vascular disease in type 2 diabetes. In I Obrosova, MJ Stevens, A Yörek (ed.), Studies in Diabetes, 149-171. New York: Springer.

Tahrani AA, Ali A, Raymond NT, Begüm S, Dubb K, Mughol S et al. (2012) Obstructive sleep apnea and diabetic neuropathy: a novel association in patients with type 2 diabetes. American Journal of Respiratory and Critical Care Medicine 186(5): 434441.

Tishler PV, Larkin EK, Schluchter MD, Redline S (2003) Incidence of sleep-disordered breathing in an urban adult population: the relative importance of risk factors in the development of sleep disordered breathing. JAMA 289(17): 2230-2237.

Vale J, Manuel P, Oliveira E, Oliveira AR, Silva E, Melo V et al. (2015) Obstructive sleep apnea and diabetes mellitus. Revista Portuguesa de Pneumologia 21(2): 55-60.

Vasconcelos JP, Daniele TMC, Bruin PFC, Forti AC, Bruin VMS (2016) Daytime Sleepiness in patients with type 2 diabetes mellitus - a prospective cohort study. International Archives of Medicine Section: Endocrinology 9(228): 1-10.

Vgontzas A, Tan T, Bixler E, Martin L, Shubert D, Kales A (1994) Sleep apnea and sleep disruption in obese patients. Archives of Internal Medicine 154(15): 1705-1711.

Wesström J, Ulfberg J, Nilsson S (2005). Sleep apnea and hormone replacement therapy: a pilot study and a literature review. Acta Obstetricia et Gynecologica Scandinavica 84(1): 54-57.

West SD, Nicoll DJ, Stradling JR (2006) Prevalence of obstructive sleep apnoea in men with type 2 diabetes. Thorax 61(11): 945-950.

Young T, Palta M, Dempsey J, Skatrud J, Weber S, Badr S (1993) The occurrence of sleep-disordered breathing among middle-aged adults. The New England Journal of Medicine 328(17): 1230-1235.

Young T, Shahar E, Nieto FJ, Redline S, Newman AB, Gottlieb DJ et al. (2002) Predictors of sleep-disordered breathing in community-dwelling adults: the sleep heart health study. Archives of Internal Medicine 162(8): 893-900.

Young T, Peppard PE, Taheri S (2005) Excess weight and sleep-disordered breathing. Journal of Applied Physiology 99(4): 1592-1599. 